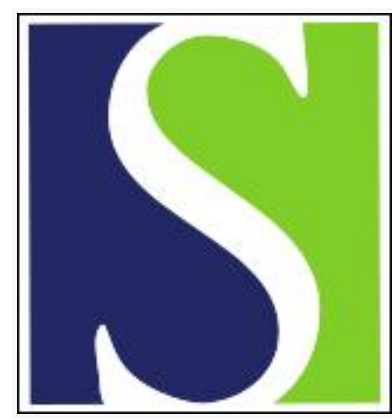

Scand J Work Environ Health 1995;21(3):165-178

https://doi.org/10.5271/sjweh.25

Issue date: Jun 1995

Possible mechanisms for the respiratory tract effects of noncarcinogenic indoor-climate pollutants and bases for their risk assessment

by Damgård Nielsen G, Alarie Y, Melchior Poulsen O, Andersen Nexø B

Key terms: asthma; neurogenic effect; occupational exposure limit; pulmonary toxicity; vagal effect

This article in PubMed: www.ncbi.nlm.nih.gov/pubmed/7481604

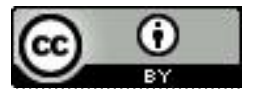




\title{
Possible mechanisms for the respiratory tract effects of noncarcinogenic indoor-climate pollutants and bases for their risk assessment
}

\author{
by Gunnar Damgård Nielsen, PhD, ${ }^{1}$ Yves Alarie, PhD, ${ }^{2}$ Otto Melchior Poulsen, PhD, ${ }^{1}$ \\ Bjørn Andersen Nexø, PhD'
}

\begin{abstract}
Damgård Nielsen G, Alarie Y, Melchior Poulsen 0, Andersen Nexø B. Possible mechanisms for the respiratory tract effects of noncarcinogenic indoor-climate pollutants and bases for their risk assessment. Scand $J$ Work Environ Health 1995;21:165-78.

This review outlines the effects of pollutants on the lungs. Mechanisms and effects relevant to the assessment of indoor-air risk are especially dealt with. Important mediators have also been considered. Concentration-effect relationships exist for toxic reactions, sensitization reactions, and neurogenic effects. If Harber's Law is used for extrapolations from higher concentrations to the lower indoor-air levels, the indoor-air risk estimate may exceed the real risk. Additivity seems to apply to toxic and neurogenic effects of low doses. Only already sensitized subjects and possible subjects with a profound alpha ${ }_{1}$-antitrypsin deficiency appear to be extremely sensitive, and a safety factor of 10 seems adequate for the protection of other groups. Thus combining occupational exposure limits (OEL), Harber's Law, and the safety factor suggests that no direct lung effects should be expected from a substance if the exposure level does not exceed 1/40 OEL.
\end{abstract}

Key terms asthma, neurogenic effects, occupational exposure limits, pulmonary toxicity, vagal effects.

The sick-building syndrome and building-related illnesses are often associated with one or more of four types of effects. One type is a surface effect on the membranes of the eyes and the upper airways. Typical symptoms are sensory irritation, nasal stuffiness, and rhinorrhea $(1-6)$. A second type occurs along the conducting airways of the lungs and at the alveolar level (eg, cough, shortness of breath, chest tightness, and wheezing) (1-6). General manifestations, typically headache, tiredness, fatigue, nausea, and dizziness $(1-6)$, constitute a third group of effects. Symptoms of the skin [eg, dryness and irritation (1-3)] belong to the fourth group.

Except for asthma, rhinitis, and hypersensitivity pneumonitis induced by indoor air (2), little attention has been paid to the mechanisms of respiratory tract effects of indoor-climate pollutants. In general, both the direct biological effects and the psychological effects (7), for example, stress, heavy work load and conflicting demands (6), can influence the number and severity of reported complaints. Thus knowing the mechanisms and their verifications is important for preventive purposes, risk assessments, and elucidation of findings in problem buildings.

This review thus deals with the possible mechanisms of the direct effects of indoor climate pollutants on the lower respiratory tract and risk assessment aspects. We propose that preliminary risk assessment of indoor-air pollutants be based on existing occupational exposure limits (OEL).

\section{Pulmonary toxicity}

General

Many xenobiotics, including air pollutants, pesticides and drugs, can affect the lower respiratory tract, either when inhaled or when reaching the lungs via the bloodstream $(8,9)$. Ozone, a typical oxidant air pollutant, can cause eye irritation, sore throat and pulmonary symptoms such as cough and chest discomfort. Furthermore, high levels of outdoor oxidant and particulate matter

1 National Institute of Occupational Health, Lers $\varnothing$ Parkallé 105, DK-2100 Copenhagen $\emptyset$, Denmark.

2 University of Pittsburgh, Department of Environmental and Occupational Health, 260 Kappa Drive, Pittsburgh, PA 15238, USA.

Reprint requests to: Dr G Damgård Nielsen, National Institute of Occupational Health, Lersø Parkallé 105, DK-2100 Copenhagen $\emptyset$, Denmark. 
have been associated with decreased athletic performance (10). Xenobiotic-induced lung injury can be divided into immunologic (cell-mediated and humoral-mediated) and nonimmunologic responses (9). However, immunologic reactions can also activate nonspecific defense mechanisms and vice versa, the reactions becoming intermingled. Regardless of the mechanism of injury, progression of an induced pulmonary toxicity reaction often results in a similar histopathologic picture with pulmonary edema, desquamation of epithelial cells, and the recruitment of inflammatory cells. Furthermore, pulmonary fibrosis can develop (9).

Only a limited number of exposures and substances in indoor air is known to cause pulmonary effects. (Asthma has been dealt with in a separate section.) Thus environmental tobacco smoke can increase the occurrence of lower respiratory illness and the frequency of chronic respiratory symptoms, and it has reduced lung function in children $(11,12)$. Wood-burning stoves can also give rise to chest illness in children $(12,13)$. The effect of the oxidant nitrogen dioxide is believed to be small at low concentrations (12). However, iceskating has resulted in exposures several times the occupational exposure limit (14), and respiratory illness has also been reported (15). Another reactive irritant, formaldehyde, can be found in many buildings. Because of its high water solubility, formaldehyde is primarily retained in the upper airways. However, exposure to it can initiate symptoms in the lungs (16) and a possible increase in bronchial hyperresponsiveness (11). These findings can be explained if formaldehyde is carried into the lungs on particles (17), as may be the case for radon in the presence of respirable particles generated by tobacco smoke (18).

\section{Activation of the macrophage-neutrophil part of the immune system}

Blood monocytes can, for example, be activated by endotoxin $(19,20)$ and particles $(20)$. They then accumulate in the lungs (19), where they release mediators (19, 20) and increase phagocytic activity (19). (See figure 1.) Alveolar macrophages derive from the blood monocytes. Growth factors, for instance, colony-stimulating factor(s) (CSF) from fibroblasts and endothelial cells, will, if released, induce a local proliferation of macrophages. The lung alveolar macrophages within the alveolar surface film provide the first line of defense in the lungs, and their purpose is, for example, to keep the alveolar surface sterile (21). Thus invading microorganisms are destroyed by released mediators and by phagocytosis $(21,22)$. Oxidants such as ozone and hydrogen peroxide (23) and possibly cigarette smoke, containing various oxidants (24), also activate alveolar macrophages.
A low number of microorganisms and, if possible, other particles can be eliminated by macrophages. However, complex interplay may occur even in this situation. Thus binding to macrophage receptors of immunoglobulins (Ig) (eg, IgG, IgE, IgA), complement system mediators, or cytokines stimulates their activity. The cytokine interferon-gamma (IFN- $\gamma$ ) especially, but also tumor necrosis factor, platelet-derived growth factor, colonystimulating factor, granulocyte macrophage - colonystimulating factor (GM-CSF), and the interleukins (IL), IL-1, IL-2, IL-4, IL-10, are able to activate or prime macrophages (21).

If the alveolar macrophages cannot overcome the offending exposure, they excrete chemotactic substances (figure 1), one result being the recruitment of polymorphonuclear neutrophil(s) (PMN), which constitute the next defense line of the nonspecific immune system (21, 22). The alveolar macrophages are the primary source of the proinflammatory cytokines tumor necrosis factoralpha (TNF- $\alpha$ ) and IL-1, which stimulate IL-8 secretion from a variety of pulmonary cells (epithelial cells, fibroblasts, smooth muscle cells, and endothelial cells). The macrophages also secrete IL-8. IL-8 is believed to be a major distal cytokine with acute pulmonary inflammatory effect. It belongs to a family of chemotactic cytokines (chemokines or $s c y$ family members) which exert neutrophil stimulatory and chemotactic activities (22, 23). The infusion of endotoxin thus raises the serum TNF- $\alpha$ level after about $1 \mathrm{~h}$, followed by a peak in the serum IL- 8 level by $8 \mathrm{~h}$, which correlates with maximum PMN activation (22). TNF- $\alpha$ has also recently been shown to be a major mediator of the toxic alveolitis induced by cotton dust and characterized by lung PMN inflammation and an elevated level of protein in bronchoalveolar lavage (BAL) fluid (25). The oxidants ozone and hydrogen peroxide can directly induce the expression of the neutrophil chemotactic factor macrophage inflammatory protein 2 (MIP-2). A direct correlation has thus been found between oxidant exposure, MIP-2 expression, and PMN accumulation in BAL fluid (23).

Bacterial-derived polypeptides and endotoxin can directly recruit PMN to the lungs and activate them (24, 26). However, inflammatory mediators such as IL- 8 and platelet-activating factor, the arachidonic acid metabolites leukotriene $\mathrm{B}_{4}$ and 5-hydroxyeicosatetraenoic acid, and serum complement are considered to be the major chemoattractants $(24,27)$. PMN contribute to the pool of inflammatory mediators by releasing leukotriene $B_{4}$, platelet-derived growth factor, IL-1, and IL-8 (24).

PMN are very important in the defense of lungs against bacterial and fungal infections. They release substantial amounts of reactive oxygen metabolites (eg, superoxide anion, hydrogen peroxide, hypochlorite, and hydroxy radicals), and therefore account for a large part 


\section{Recruitment and \\ Cells \\ Important \\ Effect activation mediators}

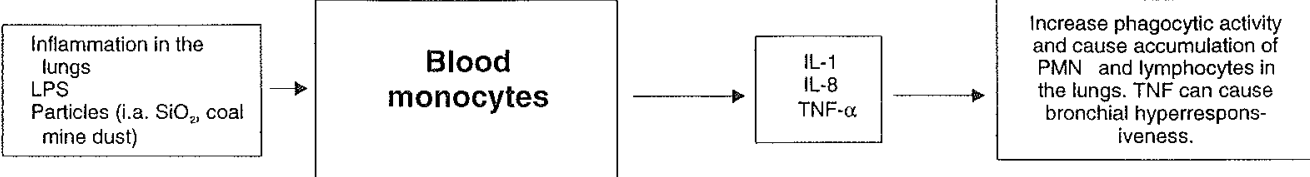

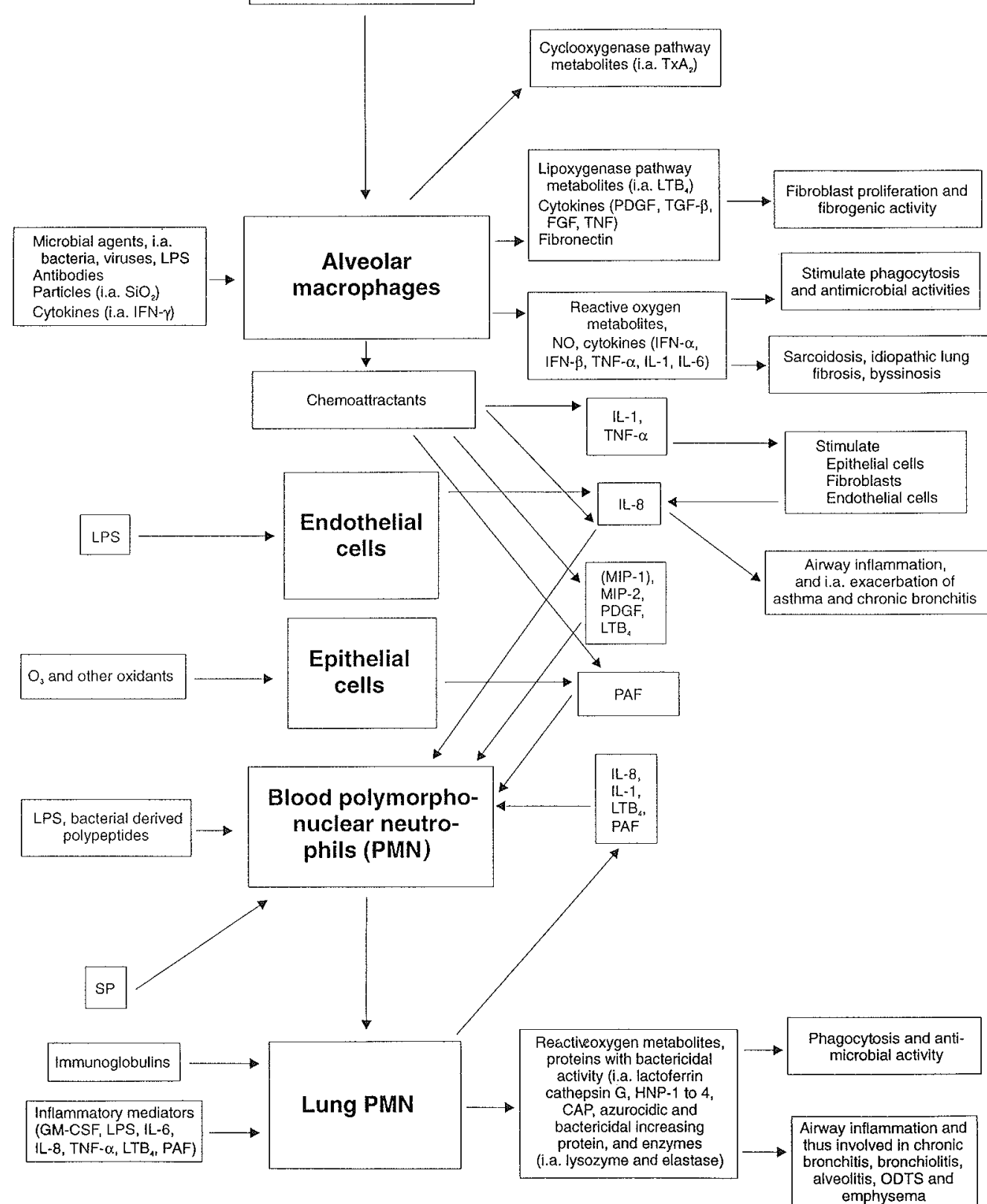

Figure 1. Simplified routes indicating important systems and mediators of the lung defense systems. Mechanisms of pathological processes are also outlined. The scheme was set up according to information from recent reports $(19-22,24-27,36)$. [CAP = cationic antimicrobial protein, FGF = fibroblast growth factor, LPS = endotoxin/lipopolysaccharide, GM-CSF = granulocyte macrophage-colony-stimulating factor, HNP-1 to HNP4 = human neutrophil peptides (defensins), IFN = interferon(s) (eg, IFN- $\alpha$, IFN- $\beta$, IFN- $\gamma$ ), IL = interleukin(s) (eg, IL- 1, IL-6, IL-8), LTB ${ }_{4}=$ leukotriene $\mathrm{B}_{4}, \mathrm{MIP}-1$ and MIP-2 = macrophage inflammatory protein(s), NO = nitrogen oxide, $\mathrm{PAF}=$ platelet activating factor, $\mathrm{O}_{3}=$ ozone, 0 DTS $=$ organic dust toxic syndrome, $\mathrm{SP}=$ substance $\mathrm{P}, \mathrm{PMN}=$ polymorphonuclear neutrophil(s), $\mathrm{PDGF}=$ platelet-derived growth factor, $\mathrm{SiO}_{2}=\mathrm{Silica}_{1} \mathrm{TXA}_{2}=$ thromboxane $A_{2}$, TGF = transforming growth factor(s) (eg, TGF- $\beta$ ), TNF = tumor necrosis factor(s) (eg, TNF- $\left.\alpha\right)$ ] 
of PMN antimicrobial activity. Furthermore, PMN release bactericidal proteins and proteolytic enzymes (eg, elastase). The cytotoxic and proteolytic materials can damage the lungs too. Thus PMN may contribute to inflammation, bronchial damage, and mucus hypersecretion in chronic bronchitis. Elastase release is involved in the development of the chronic disease emphysema (24). The ability of PMN to secrete proteinases depends highly on the type of exposure (eg, seen from exposure effects of the "inactive" inorganic titanium dioxide versus the "active" silica). The proteinase secretion is not a result of the phagocytosis of particles, but is rather due to inflammatory mediators such as cytokines (28). PMN can also give rise to airway hyperreactivity (24) and alveolitis (27).

Ozone exposure can result in bronchiolitis, and the reaction may constitute an analogy to the respiratory bronchiolitis that is associated with tobacco smoking (29). Higher environmental ozone exposures have also been shown to be associated with asthma and abnormal lung function in children (30). Acute inflammation in the lungs with fever, chills, and malaise has been observed some hours after occupational exposure to organic dust, termed organic dust toxic syndrome. This reaction is probably caused by bacterial products such as the biologically potent endotoxins and is believed to be due to a direct activation of the macrophage-neutrophil system (31). Thus oxidants and other reactive substances are important candidates as indoor pollutants with toxic effects on the lungs. Organic dust may also be important.

The opposite type of reaction, a decrease in the chemotaxis of PMN has also been described in relation to occupational exposure to n-hexane, styrene, and lead. High environmental lead exposure also impairs chemotaxis. The effect must be specific since exposure to toluene and xylene is without effect (32).

\section{Lung epithelial cell effects}

The epithelium in the lungs is the main target of air pollutants (33). Removal of the bronchial epithelium increases the responsiveness of the underlying smooth muscles to agonists such as acetylcholine, histamine, and 5-hydroxytryptamine. The hyperresponsiveness cannot be explained by damage of the epithelial barrier, which would increase the agonist concentration in the smooth muscle compartment. Rather, the intact bronchial epithelium continuously releases relaxing factors which contribute to the regulation of bronchomotor tone. Hyperreactivity of the airways after exposure to ozone, allergen, or respiratory virus occurs in relation to inflammation or desquamation of the respiratory epithelium. Thus airway hyperreactivity is a characteristic finding in asthmatic patients, for whom epithelial destruction may be prominent at all levels of the respiratory tract (34). How- ever, airway hyperresponsiveness has been seen in exposure to sulfuric acid aerosols at concentrations at which histological examinations showed no evidence of inflammation or desquamation. The attenuated release of relaxing factors or the blunting of histamine $\mathrm{H}_{3}$ receptors, which counteract the muscle contraction induced by histamine $\mathrm{H}_{1}$ receptor and modulate the cholinergic responses, may have occurred (35).

The oxidant ozone can induce bronchial hyperactivity and transient change in lung function and also increase $\mathrm{PMN}$, inflammatory mediators, and cytokines in BAL fluid. Ozone activates the phospholipases (PL) A, C and D. $\mathrm{PLA}_{2}$, for example, liberates arachidonic acid and a lysophospholipid from phosphatidylcholine. If acetylated, the lysophospholipid is converted to plateletactivating factor. This factor may play a role in the pathogenesis of lesions associated with the inhalation of ozone. (See also figure 1.) The release suggests a threshold. Arachidonic acid is metabolized by the cyclooxygenase and the lipoxygenase pathways and therefore initiates other important mediators such as prostaglandins, thromboxanes, and leukotrienes. Thus, if stressed or injured, the airway epithelial cells can release numerous mediators and thereby contribute to local airway inflammation (36). These mediators also include toxic oxygen metabolites (eg, hydrogen peroxide) and cytokines (eg, GM-CFS, IL-6, and IL-8) $(22,36)$. The oxidant nitrogen dioxide also induces hyperresponsiveness that is mediated by the liberation of the mediator thromboxane $\mathrm{A}_{2}$ (37).

\section{Protection of lung epithelial cells against injury}

The epithelial cells are protected against injury from airborne oxidants (eg, ozone, cigarette smoke, nitrogen and sulfur oxides), as well as from indirectly induced oxidant stress (ie, endotoxins, asbestos and silica). The latter can be caused by the release of reactive species from macrophages and neutrophils or from intracellularly generated radicals (eg, by paraquat). The reactive oxygen species include the superoxide anion, the hydroxy radical, hypochlorous acid, and peroxynitrite $(38,39)$. Furthermore, the lungs are also protected against the proteolytic enzyme neutrophil elastase (40).

Epithelial cells are protected intracellularly by antioxidant enzymes to avoid toxic effects. Thus catalase converts hydrogen peroxide to water and oxygen. Glutathione peroxidase, which uses glutathione as a co-substrate, also eliminates hydrogen peroxide. The superoxide dismutase converts superoxide anions to oxygen and hydrogen peroxide (38). Glutathione S-transferase may also be involved (39). Furthermore, oxidant stress may increase the antioxidant enzyme activities $(38,39)$. On one hand, a complex interplay occurs as cytokines, as TNF- $\alpha$, primarily secreted from macrophages, and IL-1 
can increase the lung activity of superoxide dismutase, which may decrease the effect of oxidant stress. On the other hand, TNF- $\alpha$ can induce cytotoxic effects by stimulating the production of reactive oxygen species, including hydrogen peroxide and the superoxide anion (38).

Other mechanisms may also be important. A reorganization in the affected airways occurs during repeated or continuous long-term exposure to ozone $(33,41)$. It increases the number of Clara cells in the distal conducting airways, the area primarily attacked. Clara cells also secrete an anti-inflammatory $10-\mathrm{kDa}$ protein which, for example, inhibits $\mathrm{PLA}_{2}$. Thus the location of the protein is optimal for a substance that performs an oxidant scavenger role (41).

The neutrophil protease elastase is not only involved in the defense of the lungs, but it can also damage the lungs. The lung tissue is protected from proteolytic degradation by the protease inhibitor $\alpha 1$-antitrypsin. However, a variety of different genetic deficiencies is known. In Scandinavia, a profound deficiency occurs in $10^{-3}$ to $10^{-4}$ of the population. The deficiency can lead to emphysema and is in itself life-shortening. Cigarette smoking further decreases the longevity by 10 to 20 years (40).

Type I alveolar epithelial cells cover about $95 \%$ of the alveolar surface. If a substance only damages type I cells, it usually initiates mild or moderate permanent lung lesions. The defects are repaired from proliferating type II cells. If the type II cells are also destroyed, for example, in the case of some paraquat intoxications, a fatal lesion can appear. Thus type II cells are necessary for the maintenance of the alveolar surface. Fibrotic lung lesions can occur if both a severe injury and a delayed reepithelialization take place; this occurrence allows the interstitial fibroblast population to proliferate (42).

\section{Evaluation of alveolar macrophage and epithelial cell biomarkers}

Overall, some main points appear in relation to normal indoor-air exposures that in general are far below occupational exposures. The application of concentration response relationships suggests that effects caused by indoor-air exposures will also occur at higher exposures in occupational settings or in animal studies. As the indoorair effects are generally more subtle, it can be expected that only the most sensitive systems of the lungs will react. These systems are the cells involved in the specific cellular and humoral immune responses (discussed in the section on asthma), the macrophages, the epithelial cells, and the sensory nerves in the lungs. Endothelial cells and fibroblasts are at least partly protected by the mucous layer and the lung epithelial cells. Furthermore, in an in vitro exposure of endothelial cells to the oxidant nitrogen dioxide for $48 \mathrm{~h}$ at a high concentration, $5 \mathrm{ppm}$, there was no effect on the cell morphology, although the serine uptake and incorporation into cellular lipids, including phosphatidylethanolamine and phosphatidylcholine, were increased (43). However, endothelial cells are easily reached from the blood stream. If the cells are injured, interstitial pulmonary edema can result. Inflammatory mediators such as TNF and reactive oxygen species can be implicated in endothelial cell damage too (9). In relation to alveolitis, invasion of alveoli by fibroblasts and the development of pulmonary fibrosis can occur $(9,42)$. However, neither primary endothelial cell injury nor fibrosis is considered relevant in relation to normal indoor-air exposures.

The interleukins TNF- $\alpha$ and IL-1, determined by $\mathrm{BAL}$, can be used as markers of macrophage stress. The alveolar macrophage MIP-2 expression was not a more sensitive indicator than the increase in PMN in BAL fluid (23). Stress of the epithelial cells can result in the excretion of platelet-activating factor, arachidonic acid metabolites, and cytokines, including IL-8. These biomarkers may also occur from other cells. However, it might well be the case that some of the cytokines furnish more sensitive indicators than the PMN increase in BAL fluid. Thus they may be able to indicate whether an indoor-air exposure can affect a specific type of biological system. However, although they may be less sensitive, classical toxicologic parameters such as an increase in proteins and PMN in BAL fluid and histopathological investigations provide a much broader screening for adverse effects, and the results can be directly related to clinical effects in humans.

\section{Groups at increased risk}

Children may be particularly sensitive to substances with effects on the lungs, as suggested from the effects of environmental tobacco smoke (12) and living in homes heated by a wood-burning stove (13). Sensitivity to the oxidant nitrogen dioxide has not been established unequivocally however (44). Further information on the effects on lung function among children have been obtained from air pollution episodes. Ozone effects have suggested that a sensitive subgroup of children may exist, whereas heterogeneous responses to suspended particles were rather due to sampling variability (45). The sensitivity may also depend on the end point investigated. Neonatal rats were more sensitive to the ozoneinduced stimulation of pulmonary arachidonic acid metabolism, as well as to the slough off of epithelial cells, than young adults were. In contrast, protein extravasation into the airways and the total number of leukocytes in BAL fluid have shown minimal or no evidence of age dependence (46).

An extensive study with adults found that acute ozone response did not show gender or race differences (47). 
However, women may show an increased sensitivity in special periods. Thus the ozone-induced decrease of lung function in young adult women reached a maximum in the follicular menstrual cycle phase, where the progesterone level is lowest. As progesterone may inhibit the production of prostaglandins, a decrease in anti-inflammatory effect may offer an explanation (48). Pregnant women and pregnant or lactating rats have also been found to be more susceptible to ozone-induced pulmonary inflammation (49). Several epidemiologic studies have investigated the effect of recurrent ozone exposure on humans. In general, a convincing association between chronic exposure and differences in lung function performance or respiratory symptoms has not been demonstrated (50).

Age was found to be a significant predictor of ozoneinduced effect on lung function among men 18 to 32 years of age (51). The older subjects were the least sensitive. Healthy men and women, aged 60 to 76 years, were not at increased risk for adverse respiratory effects from the inhalation of sulfuric acid aerosols (52). This finding suggests that healthy elderly subjects do not per se constitute an especially sensitive group. However, sensitive subgroups may exist among the elderly. Thus the reduction induced in lung function by nitrogen dioxide was greater among smokers than never-smokers. Elderly subjects with chronic obstructive pulmonary disease are slightly more sensitive to nitrogen dioxide than elderly normal subjects (53).

The fact that asthmatics are sensitive to environmental irritants is suggested by the effect of environmental tobacco smoke. The intensity of the symptoms cough, headache, and chest tightness was significantly greater in asthmatics than in nonasthmatics. However, asthmatics only reported intensities from less than "trace" to less than "minimal." The prominent symptoms were unpleasant odor (rated from "moderate" to "severe"), eye irritation (about "moderate" to "severe") and nasal discharge (about "trace" to "minimal"); the levels were not significantly different from the levels in nonasthmatics. A higher response in asthmatics may be due to an increase in airway hyperactivity or to fear of a smoking environment (54). A recent review on environmental tobacco smoke generally reached the same type of conclusion (55). The irritant ozone has been studied in several controlled chamber experiments, and in most of them asthmatic subjects were not especially sensitive either (56). In contrast, older subjects with asthma were slightly more sensitive to an inhaled sulfuric acid aerosol than healthy controls were (52).

Normal lungs are protected from destruction by the elastase released from neutrophils. Subjects with a profound $\alpha 1$-antitrypsin deficiency are not protected from this effect, and thus they are especially vulnerable to airborne exposures that give rise to inflammatory lung reactions. Therefore, the destruction process is substantially accelerated, for example, by cigarette smoking (40).

\section{Evaluation}

In toxicology, extrapolation from high- to low-dose responses has always been a problematic task. It includes extrapolation from effects at occupational exposure levels to effects at indoor-climate levels. A scientifically sound approach can be applied if Harber's Law is obeyed. It states that the effect is determined by the cumulative dose $(\mathrm{C} \cdot \mathrm{t}=\mathrm{K})$, determined by the product of the concentration $(\mathrm{C})$ and the exposure time $(\mathrm{t})$.

The applicability of Harber's Law has been investigated with rats repeatedly exposed to ozone $(0.2-8 \mathrm{ppm})$ and nitrogen dioxide (3.6--14.4 ppm), as well as their combinations. Different end points (protein, epithelial cells and PMN in BAL fluid) were studied. For most of the effects, the results at the higher concentrations were in accordance with the Law. However, at the lowest concentrations the toxicity was significantly lower than would have been predicted by the Law (57). The interaction experiments are more difficult to interpret since ozone and nitrogen dioxide react to form the potent lung toxicant nitrogen pentoxide (58). Nevertheless, at the lower concentrations, the effects of the mixtures were approximately additive, whereas the effects at the higher concentrations showed synergistic interactions (57-59). The interaction experiments demonstrated endpoint specific thresholds below which synergistic effects were not found. These thresholds were higher than the concentrations encountered in normal environmental or occupational settings (58). If these results can be generalized, they have an important implication. The low-level responses estimated from Harber's Law will overestimate the real responses. In addition, if it is assumed that the effect of mixtures at low concentrations is the sum of the estimated low-level effects, the result will be that the effect of the mixture is overestimated too.

Data from humans also exist. Formaldehyde exposures in mobile homes were determined, together with symptoms (16 were studied) and health conditions. Formaldehyde often acted independently. However, in relation to some of the symptoms (fatigue, sleeping problems, and sore throat) a greater interaction effect was possible with formaldehyde and chronic diseases, defined as asthma, hay fever, emphysema, rashes, chronic bronchitis, and allergies (60). The influence of outdoorair pollutants, airborne particles and ozone, on the hospital admissions of persons aged 65 years and older has recently been studied (61). Ozone and particles made independent contributions to the pneumonia hospitalizations. The mentioned examples of interactions on the lungs represent the general experiences. Thus the effect 
can be dominated by one substance, or each substance can act independently and the effect of the mixture can be the sum of the effect of each substance (ie, additive). In addition the effect can be more than additive (ie, synergistic). A recent review showed that the effect of mixtures tends to be additive (62) or, as indoor-air concentrations are often very low compared with the noeffect levels of the single substances, no combined action or interactions will be expected (63). Thus these results reasonably agree with those of animal studies.

Only a few of the potentially sensitive groups are believed to be of practical importance. The increased sensitivity of children has not been found to be excessive and may therefore be handled through the use of a small safety factor in risk assessments. Subjects with $\alpha 1$-antitrypsin deficiency should be protected from indoor-air concentrations of substances with inflammatory effects. On the other hand, it will probably not be possible to protect all asthmatics, as even a pure odor response may trigger an asthma reaction. Nevertheless, experiences of occupational exposure effects, including exposure limit documentation, combined with Harber's Law and the additivity concept, may clearly be very valuable in the estimation of lung effects of indoor-air pollutants.

A major problem arises when some specific substances are used as indicator substances for potentially harmful mixtures, especially for ozone, nitrogen dioxide, and particulate matter. In such cases definite indoor-air exposure limits should be established.

\section{Asthma}

\section{General}

The prevalence of asthma has increased in most industrialized countries (64-66). Environmental factors must play a major role, as the trend was seen when people moved from rural areas to urban surroundings (65). The same conclusion was reached in a Finnish study comparing asthma in a cohort of identical twins (67). The most important sources of indoor allergens are mites, pets, fungi, and rodents (64). Building-related asthma is often due either to damage to a building by water or to humidifiers or the biocides used in humidifiers (68).

Asthma manifests itself as bronchial hyperreactivity (ie, exaggerated bronchoconstrictive response on exposure to histamine, cholinergic agents, hyperventilation, cold air, and exercise) $(66,69)$. However, no correlation was found between lung function and exposure to emissions from four building materials (70). Asthmatics have also been exposed to a mixture of 22 organic vapors modeling typical indoor-air exposures. Exposure to 25 $\mathrm{mg} \cdot \mathrm{m}^{-3}$ resulted in a progressive slight fall in forced expiratory volume in $1 \mathrm{~s}$. After $2 \mathrm{~h}$ the decrease was only $10 \%$, a nonsignificant value. No decrease was seen at
$2.5 \mathrm{mg} \cdot \mathrm{m}^{-3}$, a rather high but not unusual indoor-air concentration (71). Thus, in relation to asthma, risk assessment should focus on data on the sensitization process rather than on possible exaggerated bronchoconstrictive response to nonreactive organic chemicals generally present indoors.

\section{Mechanisms of cellular and humoral immune responses}

Lymphocytes are responsible for cell-mediated and humoral (antibody-mediated) immune responses. However, lymphocytes must first be activated before they can respond to an antigen. This activation is caused by accessory cells, also termed antigen-presenting cells. Dendritic cells and Langerhans' cells are the accessory cells of major importance. Dendritic cells constitute a very minor part of the blood mononuclear cells. Both lipopolysaccharide and IFN- $\gamma$ can recruit dendritic cells to the lungs. The cytokine, GM-CSF, derived from epithelial cells can be involved both in the recruitment and in the differentiation of dendritic cells into Langerhans' cells. The intraepithelial accessory cells can capture antigens and carry them to the regional lymphatic tissue. The partially degraded antigen is expressed on the surface in association with major histocompatibility complex (MHC) molecules. Then, activation of "naive or virgin" $\mathrm{T}$ lymphocytes (not previously activated) occurs from the recognition of the antigen-MHC complex. Accessory cells are not recovered by BAL from normal subjects, contrary to that from smokers (72). The role of irritants in the activation of the immune response (adjuvant effect) is discussed in a later section.

The activated lymphocytes recirculate within the lungs. An antigenic challenge (including bacterial products such as lipopolysaccharide) and the induced cytokines (such as IL-1, IL-8, IFN- $\gamma$ and TNF- $\alpha$ ) recruit antigen-specific $\mathrm{T}$ cells to sites of inflammation. The cells include cytotoxic cells. A challenge may also initiate the synthesis of immunoglobulins (mainly $\operatorname{IgA}$ and $\mathrm{IgG}$ ) in antigen-specific $\mathrm{B}$ cells. The immunoglobulins are involved in killing microorganisms, and they, for example, facilitate bacterial phagocytosis by macrophages. Lymphocytes are involved in hypersensitivity pneumonitis and asthma (73), two diseases of importance in building-related illnesses (74). The T-cell immune system can be adversely affected [for example, from shortterm ozone inhalation (75)], a finding suggesting that both direct toxic effects and adjuvant effects may modulate the responses to allergens.

\section{Characterization}

Asthma is characterized by reversible airway obstruction caused by smooth muscle constriction, mucus secretion, 
eosinophilic inflammation along the conducting airways (76-78), and symptoms such as cough, dyspnea, wheezing, and chest tightness (77). The bronchoconstriction of the immediate reaction begins a few minutes after the exposure. It usually reaches a maximum within $30 \mathrm{~min}$ and resolves within $2 \mathrm{~h}$. The late type of reaction usually occurs 2 to $9 \mathrm{~h}$ after the exposure and resolves within $24 \mathrm{~h}(77,78)$. Asthma is usually associated with nonspecific bronchial hyperreactivity (78). Characteristically, the IgE-mediated (or IgG-mediated) bronchial response includes an early asthmatic response triggered by mast cells or basophils (79); this response can then be followed by a late response. An isolated late response is more common among individuals with asthma caused by low molecular-weight chemicals with a non-IgE-mediated reaction $(76-78)$.

Occupational asthma is a satisfactory model for asthma from the physiological and epidemiologic points of view $(80,81)$. As concentrations of offending agents are the critical factor determining sensitization (76), high levels of exposure in occupational settings can show which substances are potential sensitizers in indoor climates. Extensive lists of agents causing occupational asthma are also available (82). Furthermore, as extended periods of exposure to low levels of offending agents have not resulted in the development of sensitized states (76), risk assessment of indoor-air concentrations, if based on occupational experience, would be expected to exaggerate the risks.

Important mechanisms in asthma, including occupational asthma, have been obtained from recent reports and reviews $(21,66,69,72,73,76-79,81-85)$; they are outlined in figure 2 . In general, high molecularweight substances (proteins, polysaccharides, hapten protein conjugates) induce sensitization mediated by $\operatorname{IgE}$ (or IgG or both) via inhalation. Some of the low molecularweight chemicals, often reactive $(86,87)$, act as haptens and combine with respiratory proteins to form immunogens. This may be the case, for example, for diisocyanates, acid anhydrides, and salts of nickel and platinum. However, IgE-mediated reactions cannot account for the majority of the asthma cases induced by low molecular-weight compounds. Accidents with toxic irritant exposures have given rise to asthma (reactive airway dysfunction syndrome) $(77,82)$. Pharmacological agents, such as aspirin, a nonsteroidal anti-inflammatory drug, can also induce asthma. Nonsteroidal anti-inflammatory drugs inhibit the cyclooxygenase and thereby shift the arachidonic acid metabolism from the cyclooxygenase pathway to the 5-lipoxygenase pathway, producing leukotrienes which are potent bronchoconstrictors (88). Other mechanisms may also exist, but only the IgE- and non-IgE-mediated mechanisms mentioned in figure 2 are considered relevant for indoor-air reactions. Exposure to ozone, nitrogen dioxide, and sulfur dioxide can be asso- ciated with a transient increase in nonspecific bronchial hyperreactivity due to a reversible increase in neutrophils in the epithelium (78). An inflammatory reaction may also explain the this type of hyperreactivity in asthma $(66,69)$.

\section{Groups at increased risk}

The development of asthma can be modulated by factors such as age, type of exposure, and pattern of reaction on exposure to the agent (80). Atopy is often a predisposing factor for IgE-mediated asthma from high molecularweight compounds $(65,66,78,80,89)$. IgE-mediated asthma caused by low molecular-weight compounds may or may not be associated with atopy $(78,82)$. However, most low molecular-weight compounds induce asthma through a non-IgE-dependent mechanism (82), and with this mechanism, atopy is not a predisposing factor $(66$, $78,80,90)$.

Enhanced sensitization with antigens can be seen in laboratory animals with prior exposure to ozone, nitrogen dioxide, or sulfur dioxide $(66,78)$. Thus exposure to irritants or upper-respiratory viral infections may function as "adjuvants" by giving rise to inflammation or an enhanced penetration of allergens through mucosal barriers $(66,90)$. Tobacco smoke is a strong irritant (66) and can serve as an adjuvant. Thus exposure to environmental tobacco smoke is significantly associated with the development of asthma (91). An increased risk of asthma was also significantly associated with ambient ozone exposure in humans (91). In general, smoking enhances IgE-mediated responses $(65,76,82,89)$ but is not believed to enhance the sensitization due to low molecular-weight compounds by the non-IgE-mediated mechanism $(78,82)$.

\section{Evaluation}

Occupational exposures constitute the most extensive collection of data on asthma due to low molecular-weight compounds. Sensitization to these compounds seems to be less influenced by atopy and adjuvant effects. Industrial air is also in general more polluted than indoor-air in, for example, office buildings and private houses. Consequently, the adjuvant effects may well be less in nonindustrialized settings.

The adjuvant effect can be addressed from the point of view of environmental pollution. Industrialized areas in the former East Germany have much higher concentrations of sulfur dioxide and particulate matter than industrialized cities in West Germany. Conversely, nitrogen dioxide levels tend to be higher in West Germany. The true prevalence of asthma seems to be lower in the area of former East Germany than in West Germany. Thus the "western" style of housing with decreased ven- 


\section{Possible types of reaction}

\section{IgE-mediated}

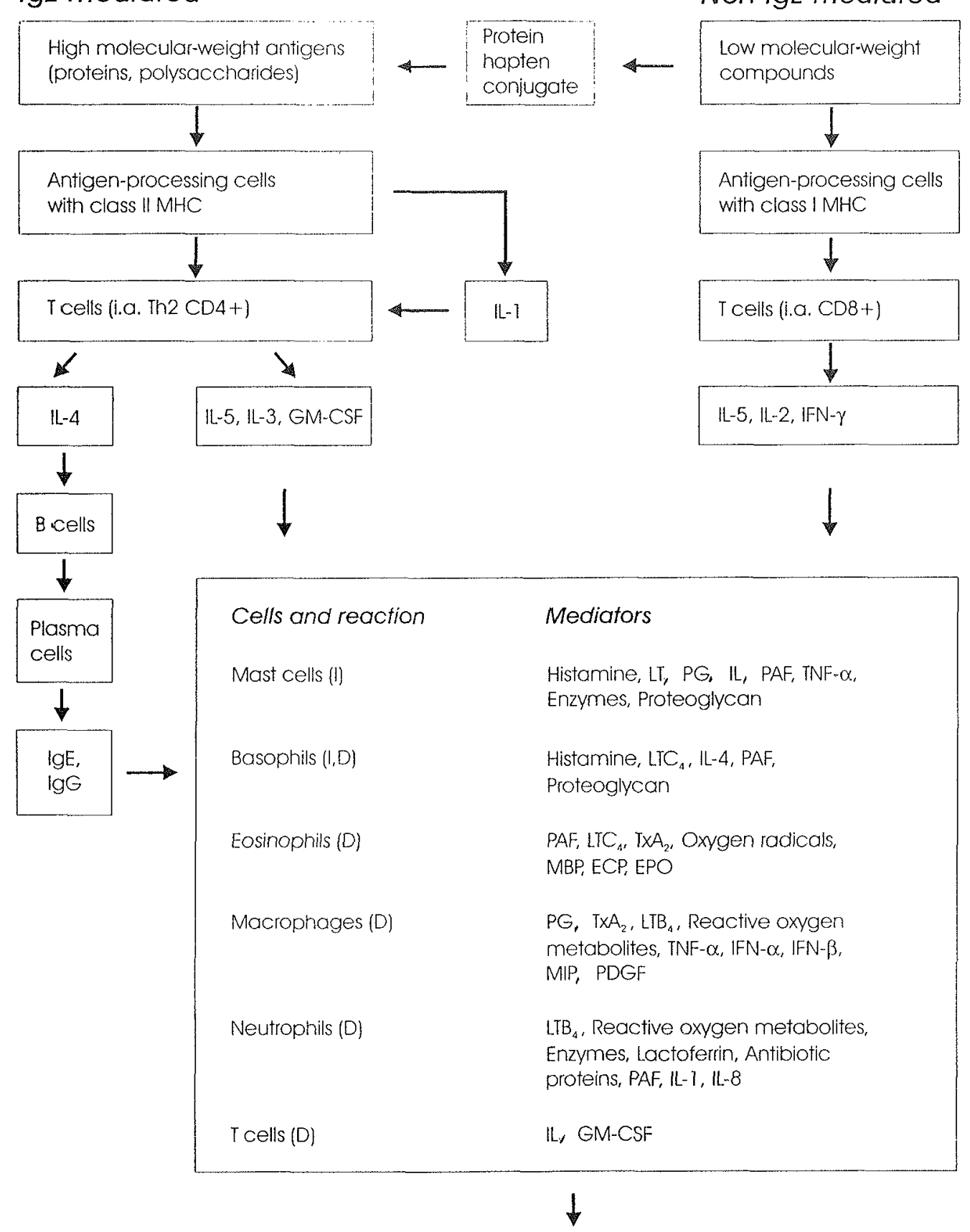

Non-IgE-mediated

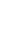


tilation, higher humidity, and probably a higher number of house dust mites and pets may be important to the prevalence of asthma. As an alternative, the heavier traffic exhaust in West Germany may explain the findings (92). The latter hypothesis is supported by the results of a recent epidemiologic investigation (93).

Clearly, occupational data can be used for risk assessment with indoor-air exposure to volatile organic compounds. Thus experience with respiratory allergy to low molecular-weight chemicals is generally derived from occupational rather than consumer exposure (84). The risk may be overestimated since short periods of high exposure are more important than the equivalent "dose" accumulated at a lower exposure over a longer period $(76,84,89)$. However, a difference in sensitivity between children and adults cannot be assessed from these data. In addition, for humans already sensitized to a given material, no method currently exists with which to identify an exposure below which adverse effects are unlikely (84).

\section{Neurogenic effects}

\section{General}

There are two main groups of chemosensitive lung receptors, the rapidly-adapting stretch receptors ("irritant receptors") and the C-fiber receptors. Both types of receptors are distributed throughout the tracheobronchial tree. Furthermore, C-fiber receptors are also found in the alveolar wall, where they are also called $\mathbf{J}$ receptors. Irritant receptors are stimulated by airborne substances (eg, ammonia, sulfur dioxide, ether, and cigarette smoke) and by endogenous mediators (eg, histamine, prostaglandin, 5-hydroxytryptamine, and acetylcholine) (94). The C-fiber receptors are a heterogeneous group of receptors which differ in susceptibility to chemical stimuli (95). They are also stimulated by the mentioned endogenous mediators $(94,95)$. Gases and vapors (eg, ammonia, chlorine, sulfur dioxide, halothane, trichlorethylene, ether, and chloroform) also stimulate C-fiber receptors (95).

Inhaling ammonia or citric acid aerosols causes rawness and irritation (94), and prostaglandins and bradykinin cause irritation and cough (95). Asthmatic attacks cause chest tightness (94). In general, the mentioned symptoms can be blocked, for example, by local anesthetics that demonstrate vagally mediated effects (94). It is believed that C-fiber afferents are important when cough and sensations are evoked by chemical stimulation (95). Symptoms from the lungs are relevant in relation to indoor-air exposures. Thus cough, wheezing, and a high frequency of airway infections are among the characteristic findings of the sick-building syndrome (1).

\section{Mechanisms}

The sensory nerves in the lungs can be activated directly by airborne substances (94-98). They can also be activated indirectly (eg, in the case of ozone, which releases cyclooxygenase products as prostaglandins). Then, the prostaglandins can stimulate pulmonary neural afferents and thereby initiate cough (48).

The $C$ fibers in the sensory nerves of the lungs have an efferent function, in addition to their afferent nerve function. Thus irritant-induced activation of the $\mathrm{C}$ fibers results in the local release of neuropeptides (including substance $\mathrm{P}$, neurokinin $\mathrm{A}$, and calcitonin gene-related peptides). Neuropeptides can cause vasodilatation and edema, termed neurogenic inflammation. The cell-surface enzyme neutral endopeptidase down regulates neurogenic inflammations by degrading substance P. Neurogenic inflammations can be enhanced by substances which decrease the activity of the neutral endopeptidase $(99,100)$. Substance P can increase phagocytosis, oxidative metabolism, and lysosomal enzyme release. It is a poor chemoattractant for PMN. However, substance $\mathrm{P}$ can interact positively with leukotriene and mast cells and increase the recruitment of PMN (27).

The sensory nerves of the lungs have been proposed to be involved in several reactions related to indoor climate, for example, multiple chemical sensitivity, the sick-building syndrome, and the reactive airway dysfunction syndrome. The last-mentioned can arise after a single toxic exposure to an irritant (eg, dust, smoke, or a solvent). Persistent bronchial hyperactivity and chronic asthma-like reactions occur. Bronchial biopsy shows epithelial damage, chronic inflammation with lymphocyte infiltration, and basement membrane thickening (99, 100).

\section{Groups at increased risk}

Effects of low exposure concentrations, generally below the occupational exposure limits, have been studied in different occupational settings. The exposures have been sometimes found to be associated with a higher prevalence of symptoms, even though they were not significantly associated with lower levels of lung function (101). However, it has recently been proposed that a variant of the reactive airway dysfunction syndrome may occur as a result of a less intense and less acute exposure to irritants (102).

\section{Evaluation}

Experience with exposure-related sensations from the lungs can be obtained from controlled chamber experiments, from exposure to outdoor pollutants, and occupational exposures. Typically, the outdoor pollutants, eg, 
ozone, nitrogen dioxide, carbon monoxide, sulfur dioxide, or particulate matter (62), comprise a limited number of substances and indicator substances. Controlled chamber experiments have dealt with the outdoor pollutants and a limited number of other substances. Thus an extensive data base on exposure-related lung sensations can not be established for any of these exposures. Experience with occupational exposures, irrespective of all the limitations of these data, furnish information on a broader range of substances. Since concentration-effect relationships exist for the neurogenic lung effects (96-98), lack of effects at occupational exposure levels suggests a lack of effect at the lower indoor-air levels.

Animal experiments have been conducted using the reflex effects from the lungs $(103,104)$ as an indicator of neurogenic exposure effects $(96-98,104,105)$. However, a firm quantitative correlation between effects on animals and effects on humans has not yet been established, nor has a relationship between mediators in $\mathrm{BAL}$ fluid and sensations in humans. This situation further emphasizes the importance of occupational data.

Evidence exists showing an interaction between sensory nerves and the immune system in the lungs (27). The data on the interactions are so limited that their importance for risk assessment cannot be elucidated. Knowledge about potentially sensitive groups is also too limited to allow any conclusion.

\section{Risk assessment}

Concentration-effect relationships apply to toxic effects, sensitization, and neurogenic effects of the lungs. Noeffect levels are also believed to exist. For toxic and sensitization effects, Harber's Law seems to overestimate the low-dose risk if extrapolated from a high exposure level. As the neurogenic effects may have steep concentration-response relationships $(96,97)$, the same conclusion is suggested for this effect. The toxic effects seem to be additive at low doses. Although not investigated, such additivity is also suggested for neurogenic effects when one considers the effects on sensory nerves in the nose (106). The sensitization potential of mixtures of airborne substances would probably depend on each substance in question and the possible adjuvant effect. If sensitization effects are estimated by extrapolation from the generally more polluted occupational environments to indoor-air levels, it can be assumed that the adjuvant effects can be neglected for the non-IgE-mediated reactions.

Clearly, it would be desirable to use indoor-air standards in combination with methods evaluating the interplay between substances in mixtures in assessments of indoor-air health effects. The World Health Organization (107) has established guidelines for about 30 (carcinogenic and noncarcinogenic) substances, and Canada has guidelines for about 10 noncarcinogenic substances (108). In addition, many countries have standards for formaldehyde. Although established guidelines or standards are valuable and should be used in risk assessments, the number is insufficient for the evaluation of the health effects of the hundreds of indoor-air pollutants.

Many hundreds of occupational exposure limits and documentation for them exist. Thus there would be a tremendous saving of human and financial resources if the selection of a safe indoor-air level would start by considering these limits (109), an approach taken in this review. Using Harber's Law and accepting that the exposure limits are for $8 \mathrm{~h}$ a day, $5 \mathrm{~d}$ a week, the indoor exposure level should not exceed $(8 / 24) \cdot(5 / 7)$. OEL $\sim 1 / 4 \cdot$ OEL. In general, the working population may not include the particularly sensitive groups at increased risk. This review has indicated that the more susceptible individuals may not be that much more sensitive, except for the already sensitized or allergic subjects and for subjects with a profound $\alpha 1$-antitrypsin deficiency. For other groups at increased risk protection can be achieved with a common safety factor, often set at $10(110)$, in the standard setting procedure. Thus a preliminary indoor-air guideline for lung effects would be equal to $1 / 40 \cdot$ OEL. If none of the indoor-air substances exceed these concentrations, the substances themselves are not believed to cause health effects. If one or more concentrations fall into the "gray" range (ie, from $1 / 40$. OEL to $1 / 4$. OEL), a detailed evaluation should be carried out. Except for the sensitization effects of allergens, the effects of indoor-air mixtures of substances with the same biological effect should be considered additive $(111,112)$, as is the case for occupational exposures (113).

In conclusion, the suggested approach in which occupational exposure limits are used in a preliminary risk assessment of indoor-air concentrations may be advantageous for several reasons: it is simple, it is based on a limited number of assumptions, it has a transparent biological foundation, and it is based on existing toxicologic documentation for occupational exposure limits. This approach may save resources and time in the evaluation of the direct health effects of indoor air.

\section{Acknowledgments}

We wish to thank Maria Hammer, Britta Elsholm, Bodil Holst, and Poul Helms for their assistance with the preparation of the manuscript. This research was supported financially by the Danish Technical Research Council (STVF) as part of the research program "Healthy Buildings," 1993-1997. 


\section{References}

1. World Health Organization (WHO). Indoor air pollutants: exposure and health effects. Copenhagen: WHO, 1983. EURO reports and studies 78 .

2. Molina C, Pickering CAC, Valbjørn O, de Bortoli M. Sick building syndrome: a practical guide. Brussels: Commission of the European Communities, 1989. Report no 4.

3. Finnegan MJ, Pickering CAC, Burge PS. The sick building syndrome: prevalence studies. Br Med J 1984;289:1573—5.

4. Macher JM, Hayward SB. Public inquiries about indoor air quality in California. Environ Health Perspect 1991;92: $175-80$.

5. Hodgson MJ, Frohliger J, Permar E, Tidwell C, Traven ND, Olenchock SA, et al. Symptoms and microenvironmental measures in nonproblem buildings. J Occup Med 1991;33: $527-33$.

6. Wallace LA, Nelson CI, Highsmith R, Dunteman G. Association of personal and workplace characteristics with health, comfort and odor: a survey of 3948 office workers in three buildings. Indoor Air 1993;3:193-205.

7. Thörn $\AA$. Case report on a sick building: analysis and interpretation in the context of its disease history. Scand J Soc Med 1994;22:228-34.

8. Witschi H, Côtè MG. Primary pulmonary responses to toxic agents. CRC Crit Rev Toxicol 1977;5:23-66.

9. Hollinger MA. Drug-induced lung toxicity. J Am Coll Toxicol 1993;12:31-47.

10. Ostro BD. Examining acute health outcomes due to ozone exposure and their subsequent relationship to chronic disease outcomes. Environ Health Perspect 1993;101 suppl 4: $213-6$.

11. Nicolai T, Mutius EV. Die Münchner Allergie- und Asthmastudie und ihre Folgeuntersuchungen: Ergebnisse und Stand der derzeit laufenden Untersuchungen. GSF-Ber 1993; 31/93:217-29.

12. Samet JM, Marbury MC, Spengler JD. Health effects and sources of indoor air pollution: part I. Am Rev Respir Dis 1987; 136:1486-1508.

13. Honicky RE, Osborne JS. Respiratory effects of wood heat: clinical observations and epidemiologic assessment. Environ Health Perspect 1991;95:105-9.

14. Berglund M, Bråbäck L, Bylin G, Jonson J-O, Vahter M. Personal $\mathrm{NO}_{2}$ exposure monitoring shows high exposure among ice-skating schoolchildren. Arch Environ Health 1994:49:17-24.

15. Hedberg K, Hedberg CW, Iber $\mathrm{C}$, White KE, Osterholm MT, Jones DBW, et al. An outbreak of nitrogen dioxideinduced respiratory illness among ice hockey players. JAMA 1989;262:3014-7.

16. Samet JM, Marbury MC, Spengler JD. Health effects and sources of indoor air pollution: part II. Am Rev Respir Dis 1988; 137:221-42.

17. Lippy BE, Turner RW. Complex mixtures in industrial workspaces: lessons for indoor air quality evaluations. Environ Health Perspect 1991;95:81-3.

18. Samet JM, Lambert WE. Epidemiologic approaches for assessing health risks from complex mixtures in indoor air. Environ Health Perspect 1991;95:71-4.

19. Ohgami M, Doerschuk CM, Gie RP, English D, Hogg JC. Late effects of endotoxin on the accumulation and function of monocytes in rabbit lungs. Am Rev Respir Dis 1992; 146:190-5.

20. Jorna THJM, Schins RPF, Lenaerts L, Derhaag TJJM, Wout- ers EFM, Borm PJA. Airflow obstruction and monocyte TNF release in coal workers. Exp Lung Res 1994;20:42131.

21. Lohmann-Matthes ML, Steinmüller C, Franke-Ullmann G. Pulmonary macrophages. Eur Respir J 1994;7:1678-89.

22. Standiford TJ, Kunkel SL, Strieter RM. Interleukin-8: a major mediator of acute pulmonary inflammation. Reg Immunol 1993;5:134-41.

23. Driscoll KE, Simpson L, Carter J, Hassenbein D, Leikauf GD. Ozone inhalation stimulates expression of a nentrophil chemotactic protein, macrophage inflammatory protein 2 . Toxicol Appl Pharmacol 1993;119:306-9.

24. Sibille Y, Marchandise FX. Pulmonary immune cells in health and disease: polymorphonuclear neutrophils. Eur Respir J 1993;6:1529—43.

25. Shvedova AA, Kramarik JA, Keohavong P, Chumakov KM, Karol MH. Use of anti-TNF- $\alpha$ antiserum to investigate toxic alveolitis arising from cotton dust exposure. Exp Lung Res 1994;20:297-315.

26. Bassett DJP, Elbon CL, Ishii $Y$, Yang $H$, Otterbein L, Boswell GA, et al. EDU pretreatment decreases polymorphonuclear leukocyte migration into rat lung airways. Toxicol Appl Pharmacol 1994;127:76 - 82.

27. Mathison R, Davison JS, Befust AD. Neural regulation of neutrophil involvement in pulmonary inflammation. Comp Biochem Physiol 1993;106C:39-48.

28. Brown GM, Brown DM, Donaldson K. Inflammatory response to particles in the rat lung: secretion of acid and neutral proteinases by bronchoalveolar leucocytes. Ann Occup Hyg 1991;35:389—96.

29. Bates DV. Detection of chronic respiratory bronchiolitis in oxidant-exposed populations: analogy to tobacco smoke exposure. Environ Health Perspect 1993;101 suppl 4:217-8.

30. Schmitzberger R, Rhomberger K, Kemmler G. Chronic exposure to ozone and respiratory health of children. Lancet 1992;339:881-2.

31. Rylander R. Symptoms and mechanisms - inflammation of the lung. Am J Ind Med 1994;25:19-23.

32. Governa $M$, Valentino $M$, Vinsonà $I$. Chemotactic activity of human polymorphonuclear leukocytes and industrial xenobiotics: a brief review. Toxicology 1994;91:165-77.

33. Takahashi Y, Aida S, Suzuki E, Ito Y, Miura T, Kimula Y. Cytochrome P450 2B1 immunoreactivity in bronchiolar and alveolar epithelial cells after exposure of rats to ozone. Toxicol Appl Pharmacol 1994;128:207-15.

34. Vanhoutte PM. Epithelium-derived relaxing factor(s) and bronchial reactivity. Am Rev Respir Dis 1988;138:s24s30.

35. El-Fawal HAN, Schlesinger RB. Nonspecific airway hyperresponsiveness induced by inhalation exposure to sulfuric acid aerosol: an in vitro assessment. Toxicol Appl Pharmacol 1994;125:70-6.

36. Wright DT, Adler KB, Akley NI, Dailey LA, Friedman M. Ozone stimulates release of platelet activating factor and activates phospholipases in guinea pig tracheal epithelial cells in primary culture. Toxicol Appl Pharmacol 1994; 127:27-36.

37. Kobayashi T, Shinozaki Y. Induction of transient airway hyperresponsiveness by exposure to 4 ppm nitrogen dioxide in guinea pigs. J Toxicol Environ Health 1992;37:451—61.

38. Quinlan T, Spivack S, Mossman BT. Regulation of antioxidant enzymes in lung after oxidant injury. Environ Health Perspect 1994;102 suppl 2:79-87.

39. Plopper CG, Duan X, Buckpitt AR, Pinkerton KE. Dose- 
dependent tolerance to ozone: IV. site-specific elevation in antioxidant enzymes in the lungs of rats exposed for 90 days or 20 months. Toxicol Appl Pharmacol 1994;127:124-31.

40. Blank CA, Brantly M. Clinical features and molecular characteristics of $\alpha 1$-antitrypsin deficiency. Ann Allergy 1994; $72: 105-21$

41. Dodge DE, Rucker RB, Pinkerton KE, Haselton CJ, Plopper CG. Dose-dependent tolerance to ozone: III. elevation of intracellular Clara cell $10-\mathrm{kDa}$ protein in central acini of rats exposed for 20 months. Toxicol Appl Pharmacol 1994;127: $109-23$

42. Witschi H. Responses of the lung to toxic injury. Environ Health Perspect 1990;85:5-13.

43. Li YD, Patel JM, Block ER. Nitrogen dioxide-induced phosphatidylserine biosynthesis and subcellular translocation in cultured pulmonary artery endothelial cells. Toxicol Appl Pharmacol 1994;129:114-20.

44. Samet JM, Lambert WE, Skipper BJ, Cushing AH, McLaren LC, Schwab M, et al. A study of respiratory illnesses in infants and nitrogen dioxide exposure. Arch Environ Health 1992:47:57-63.

45. Brunekreef B, Kinney PL, Ware JH, Dockery D, Speizer FE, Spengler JD, et al. Sensitive subgroups and normal variation in pulmonary function response to air pollution episodes. Environ Health Perspect 1991;90:189—93.

46. Gunnison AF, Weideman PA, Sobo M, Koenig KL, Chen LC. Age-dependence of responses to acute ozone exposure in rats. Fundam Appl Toxicol 1992;18:360 — 9.

47. Seal E, McDonneli WF, House DE, Salaam SA, Dewitt PJ, Butler SO, et al. The pulmonary response of white and black adults to six concentrations of ozone. Am Rev Respir Dis 1993;147:804-10.

48. Fox SD, Adams WC, Brookes KA, Lasley BL. Enhanced response to ozone exposure during the follicular phase of the menstrual cycle. Environ Health Perspect 1993;101:242-4.

49. Gunnison AF, Weideman PA, Sobo M. Enhanced inflammatory response to acute ozone exposure in rats during pregnancy and lactation. Fundam Appl Toxicol 1992;19:60712.

50. Devlin RB. Identification of subpopulations that are sensitive to ozone exposure: use of end points currently available and potential use of laboratory-based end points under development. Environ Health Perspect 1993;101 suppl 4:22530.

51. McDonnell WF, Muller KE, Bromberg PA, Shy CM. Predictors of individual differences in acute response to ozone exposure. Am Rev Respir Dis 1993;147:818—25.

52. Koenig JQ, Dumler K, Rebolledo V, Williams PV, Pierson WE. Respiratory effects of inhaled sulfuric acid on senior asthmatics and nonasthmatics. Arch Environ Health 1993; 48:171-5.

53. Morrow PE, Utell MJ, Bauer MA, Smeglin AM, Frampton $\mathrm{MW}, \mathrm{Cox} \mathrm{C}$, et al. Pulmonary performance of elderly normal subjects and subjects with chronic obstructive pulmonary disease exposed to $0.3 \mathrm{ppm}$ nitrogen dioxide. Am Rev Respir Dis 1992;145:291-300.

54. Urch RB, Silverman F, Corey P, Shephard RJ. Acute symptom responses to environmental tobacco smoke in asthmatic and nonasthmatic individuals. Indoor Air 1991;1:404-13.

55. Witorsch P. Does environmental tobacco smoke (ETS) cause adverse health effects in susceptible individuals? A critical review of the scientific literature: I. respiratory disorders, atopic allergy and related conditions. Environ Technol $1992 ; 13: 323-40$
56. Balmes JR. The role of ozone exposure in the epidemiology of asthma. Environ Health Perspect 1993;101 suppl 4:219 24.

57. Gelzleichter TR, Witschi H, Last JA. Concentration-response relationships of rat lungs to exposure to oxidant air pollutants: a critical test of Haber's Law for ozone and nitrogen dioxide. Toxicol Appl Pharmacol 1992;112:73 — 80 .

58. Gelzleichter TR, Witschi H, Last JA. Synergistic interaction of nitrogen dioxide and ozone on rat lungs: acute responses. Toxicol Appl Pharmacol 1992;116:1-9.

59. Rajini P, Gelzleichter TR, Last JA, Witschi H. Alveolar and airway cell kinetics in the lungs of rats exposed to nitrogen dioxide, ozone, and a combination of the two gases. Toxicol Appl Pharmacol 1993;121:186-92.

60. Liu K-S, Huang F-Y, Hayward SB, Wesolowski J, Sexton $\mathrm{K}$. Irritant effects of formaldehyde exposure in mobile homes. Environ Health Perspect 1991;94:91-4.

61. Schwartz J. $\mathrm{PM}_{10}$, ozone, and hospital admissions for the elderly in Minneapolis-St Paul, Minnesota. Arch Environ Health 1994:49:366-74.

62. Folinsbee LJ. Human health effects of air pollution. Environ Health Perspect 1992;100:45-_.56.

63. Feron VJ, Woutersen RA, Arts JHE, Cassee FR, de Vrijer F, van Bladeren PJ. Indoor air, a variable complex mixture: strategy for selection of (combinations of) chemicals with high health hazard potential. Environ Technol 1992;13: $341-50$.

64. Munir A, Björkstén B. Indoor pollution and allergic sensitization. In: Knöppel H, Wolkoff P, editors. Chemical, microbiological, health and comfort aspects of indoor air quality - state of the art in SBS. Dordrecht: Kluwer Academic Publisher, 1992:181-99.

65. Hendrick DJ. Management of occupational asthma. Eur Respir J 1994;7:961-8.

66. Bakke JV. Overfølsomhet i luftveiene og kjemiske stoffer København: Nordisk Ministerrådet, 1993.

67. Antti-Poika M, Nordman H, Koskenvuo M, Kaprio J, Jalava M. Role of occupational exposure to airway irritants in the development of asthma. Int Arch Occup Environ Health 1992;64:195-200.

68. Hoffman RE, Wood RC, Kreiss K. Building-related asthma in Denver office workers. Am J Public health 1993;83:8993.

69. Lötvall J, Andius P. Inflammation - orsak till astmabesvär Lakartidningen 1994;91:2232-8.

70. Johnsen CR, Heinig JH, Schmidt K, Albrechtsen O, Nielsen PA, Wolkoff $P$, et al. A study of human reactions to emissions from building materials in climate chambers: part I. clinical data, performance and comfort. Indoor-air 1991;1: $377-88$.

71. Harving H, Dahl R, Mølhave L. Lung function and bronchial reactivity in asthmatics during exposure to volatile organic compounds. Am Rev Respir Dis 1991;143:751-4.

72. Hance, AJ. Pulmonary immune cells in health and disease: dendritic cells and Langerhans' cells. Eur Respir J 1993;6: 1213-20.

73. Agostini C, Chilosi M, Zambello R, Trentin R, Semenzato G. Pulmonary immune cells in health and disease: lymphocytes. Eur Respir J 1993;6:1378-401.

74. Finnegan MJ, Pickering CAC. Building related illness. Clin Allergy 1986;16:389-405.

75. Li AF-Y, Richters A. Ambient level ozone effets on subpopulations of thymocytes and spleen T lymphocytes. Arch Environ Health 1991;46:57-63. 
76. Karol MH. Allergic reactions to indoor air pollutants. Environ Health Perspect 1991;95:45-51.

77. Bernstein DI. Occupational asthma. Med Clin North Am 1992;76:917-34

78. Salvaggio JE, O'Neil CE. Pathogenic mechanisms in occupational hypersensitivity states. Immunol Allergy Clin North Am 1992;12:711-29.

79. Warner JA, Kroegel C. Pulmonary immune cells in health and disease: mast cells and basophils. Eur Respir J 1994; $7: 1326-41$

80. Malo J-L, Ghezzo H, D'Aquino C, L'Archevêque J, Cartier A, Chan-Yeung M. Natural history of occupational asthma: relevance of type of agent and other factors in the rate of development of symptoms in affected subjects. J Allergy Clin Immunol 1992;90:937 - 44.

81. Mapp CE, Saetta M, Maestrelli P, Stefano AD, Chitano P, Boschetto P, et al. Mechanisms and pathology of occupational asthma. Eur Respir J 1994;7:544—54.

82. Chan-Yeung M, Malo J-L. Aetiological agents in occupational asthma. Eur Respir J 1994;7:346—71.

83. Kroegel C, Warner JA, Virchow J-C, Matthys H. Pulmonary immune cells in health and disease: the eosinophil leucocyte (part II). Eur Respir J 1994;7:743-60.

84. Briatico-Vangosa G, Braun CJL, Cookman G, Hofmann T, Kimber I, Loveless SE, et al. Respiratory allergy: hazard identification and risk assessment. Fund Appl Toxicol 1994; 23:145-58.

85. Maestrelli P, Del Prete GF, De Carli M, D’Elios MM, Saetta M, Di Stefano A, et al. CD8 T-cell clones producing interleukin-5 and interferon-gamma in brochial mucosa of patients with asthma induced by toluene diisocyanate. Scand J Work Environ Health 1994;20:376-81.

86. Agius RM, Elton RA, Sawyer L, Taylor P. Occupational asthma and the chemical properties of low molecular weight organic substances. Occup Med 1994;44:34—6.

87. Gauggel DL, Sarlo K, Asquith TN. A proposed screen for evaluating low-molecular-weight chemicals as potential respiratory allergens. J Appl Toxicol 1993;13:307-13.

88. Hunt LW, Rosenow EC. Asthma-producing drugs. Ann Allergy 1992;68:453-62.

89. Venables KM. Epidemiology and the prevention of occupational asthma. Br J Ind Med 1987;44:73-5.

90. Karol MH. Animal models of occupational asthma. Eur Respir J 1994;7:555—68.

91. Greer JR, Abbey DE, Burchette RJ. Asthma related to occupational and ambient air pollutants in nonsmokers. J Occup Med 1993;35:909-15.

92. Magnussen H, Jörres R, Nowak D. Effect of air pollution on the prevalence of asthma and allergy: lessons from the German reunification. Thorax 1993;48:879-81.

93. Edwards J, Walters S, Griffiths RK. Hospital admissions for asthma in preschool children: relationship to major roads in Birmingham, United Kingdom. Arch Environ Health 1994; 49:223-7.

94. Widdicombe JG. Sensory innervation of the lungs and airways. Prog Brain Res 1986;67:49—64.

95. Coleridge JCG, Coleridge HM. Afferent vagal C fibre innervation of the lungs and airways and its functional significance. Rev Physiol Biochem Pharmacol 1984;99:1-110.
96. Kristiansen U, Hansen L, Nielsen GD, Holst E. Sensory irritation and pulmonary irritation of cumene and $n$-propanol: mechanisms of receptor activation and desensitization. Acta Pharmacol Toxicol 1986;59:60-72.

97. Kristiansen U, Vinggaard AM, Nielsen GD. The effects of n-butanol vapour on respiratory rate and tidal volume. Arch Toxicol 1988;61:229-36.

98. Vijayaraghavan R, Schaper M, Thompson R, Stock MF, Alarie Y. Characteristic modifications of the breathing pattern of mice to evaluate the effects of airborne chemicals on the respiratory tract. Arch Toxicol 1993;67:478-90.

99. Meggs WJ. Neurogenic inflammation and sensitivity to environmental chemicals. Environ Health Perspect 1993;101: 234-8.

100. Meggs WJ. RADS and RUDS - the toxic induction of asthma and rhinitis. J Toxicol Clin Toxicol 1994;32:487501.

101. Kremer AM, Pal TM, Boleij JSM, Schouten JP, Rijcken B. Airway hyperresponsiveness, prevalence of chronic respiratory symptoms, and lung function in workers exposed to irritants. Occup Environ Med 1994:51:3-13.

102. Kipen HM, Blume R, Hutt D. Asthma experience in an occupational and environmentál medicine clinic. J Occup Med 1994;36:1133-7.

103. Alarie Y. Sensory irritation by airborne chemicals. CRC Crit Rev Toxicol 1973;2:299--363.

104. Alarie $Y$. Toxicological evaluation of airborne chemical irritants and allergens using respiratory reflex reactions. In: Leong BKJ, editor. Proceedings of the inhalation toxicology and technology symposium. Collingwood, MI: Ann Arbor Science, 1981:207-31.

105. Schaper M, Detwiler K. Evaluation of the acute respiratory effects of aerosolized machining fluid in mice. Fund Appl Toxicol 1991;16:309-19.

106. Nielsen GD, Kristiansen U, Hansen L, Alarie Y. Irritation of the upper airways from mixtures of cumene and n-propanol: mechanisms and their consequences for setting industrial exposure limits. Arch Toxicol 1988;62:209-15.

107. World Health Organization (WHO). Air quality guidelines for Europe. Copenhagen: WHO, 1987. European series no 23.

108. Environmental Health Directorate. Exposure guidelines for residential indoor air quality. Ottawa: Department of National Health and Welfare, cat H49-58/1990E.

109. Aviado DM. Toxicological basis for regulation of indoor air quality. J Appl Toxicol 1988;8:155-7.

110. Shoaf CR. Current assessment practices for noncancer end points. Environ Health Perspect 1991;95:111 — 9.

111. Pierson TK, Hetes RG, Naugle DF. Risk characterization framework for noncancer end points. Environ Health Perspect 1991;95:121-9.

112. Rothweiler H, Schlatter C. Human exposure to volatile organic compounds in indoor air - a health risk? Toxicol Environ Chem 1993;40:93-102.

113. Holmberg B, Lundberg P. Exposure limits for mixtures. Ann Am Conf Ind Hyg 1985;12:111 -8.

Received for publication: 4 April 1995 